\title{
THE
}

\section{Blacker than Death: Recollecting the "Black Turn" in Metal Aesthetics}

Ian Reyes

University of Rhode Island, ianreyes@uri.edu

Follow this and additional works at: https://digitalcommons.uri.edu/com_facpubs

The University of Rhode Island Faculty have made this article openly available.

Please let us know how Open Access to this research benefits you.

This is a pre-publication author manuscript of the final, published article.

Terms of Use

This article is made available under the terms and conditions applicable towards Open Access

Policy Articles, as set forth in our Terms of Use.

\section{Citation/Publisher Attribution}

Reyes, I. (2013), Blacker than Death: Recollecting the "Black Turn" in Metal Aesthetics. Journal of Popular Music Studies, 25: 240-257. doi:10.1111/jpms.12026

Available online at http://dx.doi.org/10.1111/jpms.12026

This Article is brought to you for free and open access by the Communication Studies at DigitalCommons@URI. It has been accepted for inclusion in Communication Studies Faculty Publications by an authorized administrator of DigitalCommons@URI. For more information, please contact digitalcommons-group@uri.edu. 
Blacker than Death: Recollecting the "Black Turn" in Metal Aesthetics

Ian Reyes

Department of Communication Studies

Harrington School of Communication and Media

The University of Rhode Island

\section{INTRODUCTION}

This essay illuminates the construction of a newer, blacker, and heavier recollection of metal's aesthetic potential. By analyzing recordings and popular press articles, and reading these through the historical and theoretical observations of academic metal studies, I argue that the precondition of 1990s black metal was the exhaustion of death metal aesthetics coinciding with the emergence of a more international metal scene. In the 90s, death metal—once undisputedly the heaviest of all metals—had become unspectacular, too familiar, and as a result less heavy. Innovating a sound heavier than death entailed a subcultural reorientation towards recordings forgotten under death metal's hegemonic moment. In retracing black metal's sonic origins, one finds that one of the most remarkable things about its success was that black metal had previously been the sound of amateurism, incompetence, and failure. The following essay examines how such an aesthetic turn takes place.

\section{ORIGIN MYTHS}

Standard accounts of black metal's origin typically center on the legend of the "Black Circle" of Norwegian fans and bands responsible for committing a string of crimes including murder and arson in the early 1990s. Coverage of these events emphasized the criminals' "Satanic" 
worldviews as well as their opinions about the state of heavy metal music. ${ }^{i}$ Regardless of the criminals' well-documented retractions, denouncements, and revisions of the Satanic aspects of their crimes, the alleged connection between heavy metal, Satanism, and criminality continues to be the focal point of much popular and academic attention to black metal.

The problem with emphasizing black metal as a Satanic phenomenon or a Norwegian phenomenon rather than as a more global metal phenomenon is that this approach unjustifiably weds the success of a genre of music with the success of an ideology or events independent of material history, and stresses the dynamic between the dominant culture and the subculture while downplaying the aesthetic dynamics internal to the subculture. While the spectacle of purportedly Satanic crime undoubtedly propelled black metal into public consciousness, those events were overdetermined by material and cultural circumstances specific to the extreme metal subculture of the time. This moment of crisis and its solution will be referred to here as the "black turn."

The crisis of this moment may be difficult to retrieve given the ubiquity of black metal in contemporary popular culture. Today, black metal has become de rigueur, extending beyond the subculture, resulting in Grammy-winning albums and spreading into other media, including black metal themed advertisements, films, and television shows. In this context, music from or in the style of the older, original recordings addressed in this study is called "true" or "raw" black metal, distinct from the slicker imitations riding its wake.

Less true, derivative, and hybrid styles like symphonic black metal, folk metal, or Cascadian metal developed with and against this lineage. True black metal bodied forth the sonic signifiers of blackness shared by these later styles; it forms the keystone that establishes audible connections between black metal and other genres. True black was and is a distinct aesthetic due to its style of recording, which has been one of its least portable aesthetic features (unlike, for 
example, raspy vocals or repetitive, tremolo-picked guitar melodies). Given this, the dimension of black metal at issue here is its recollection and construction of a certain "raw" sound identified through an immanent critique of extreme metal aesthetics.

The original promise of black metal, in its truest or most raw form, can be summarized as a fundamentalist solution to a crisis of metal heaviness. Michael Moynihan and Didrik Soderlind's book Lords of Chaos bears witness to this fundamentalism in discussions with Oystein Aarseth, singer for Mayhem (Norway), owner of Helvete, an Oslo record shop, proprietor of the Death Like Silence label, and trendsetter within the Norwegian scene. ${ }^{\text {ii }}$ Describing the lamentable state of extreme heavy metal in the 90s, Aarseth declares: "We must take this scene to what it was in the past" (Moynihan and Soderlind 60). Exactly what that past might be, however, is left unstated. Yet such calls to remember the past and its unfulfilled possibilities were the rallying cry of black metal reformists. But where, exactly, was this critical reaction aimed?

In the 1990s, the problem was the hegemony of death metal emerging from the United States. The sound of death metal was, and largely still is, agreed to be the heaviest of all metals, even according to those who are not fans (Berger and Fales 187). Nevertheless, the idea that black metal was conceived and succeeded as a pointed challenge to death metal is widely supported by historians and theorists of heavy metal. ${ }^{\mathrm{iii}}$ Although metal had once been defined primarily by British and American music, the global network of extreme metal fans had grown significantly by the dawn of the $90 \mathrm{~s}$, at which time there were many more people participating in the subculture as well as many more ways to be heard, thanks to a proliferation of fan magazines and tape trading networks. ${ }^{\text {iv }}$ The spark of the crisis came from the expansion of the subculture, which changed the dynamics of the global dialogue on metal—especially that part concerned with what makes metal extreme, transgressive, or heavy. 
In sum, the subcultural charges against death metal amounted to two points. First, the lyrics: death metal had become more political, focusing on current events rather than on traditional metal matters like fantasy, the occult, or the supernatural. This charge makes sense, considering that a more international audience might care less about American politics and might connect more with fantasy, occult, and supernatural themes. ${ }^{\mathrm{v}}$ The second charge, which lies at the heart of the present argument, was against the sound. Death metal had become too baroque, as evidenced by overproduced recordings of music that was unduly complex. The logic behind this latter charge will be addressed in more detail below. But in short, it speaks to Harris Berger's observation that the history of metal has been one ceaseless search for ever-heavier sounds. The consensus of the globalizing metal subculture of the 1990s was that death metal had exhausted the possibilities for heaviness, reaching the heaviest point imaginable within the current paradigm, a point from which the only response seemed to be to retreat to less heavy terrain. Essentially, the black turn was the alternative to retreat.

Despite the fact that black metal is ostensibly a music-based movement, most academic studies have concentrated on its politics, imagery, lyrics, and personalities at the expense of focused analyses of the sound of the music itself. Ross Hagen found that, "Provocative as these [academic] works may be, they tend to avoid engaging the music beyond broadly descriptive terms such as 'heavy' or 'brutal'." Hagen's work significantly contributed to understanding the music, primarily through its analysis of black metal composition and guitar techniques, which noted that, "“heaviness' in black metal has been divorced somewhat from its associations with low frequencies and has instead become associated with harshness and timbral density." He went on to characterize the "true" black sound as "lo-fi" and "low-budget," the antithesis of what American death metal had become. 
The present study supports the notion of black metal as a rejection of dominant production values by examining discourses concerning the recollection and use of recordings as raw materials for the subcultural memory-work entailed in warranting this sound. Recollection is a particular modality of memory-work, which "concerns our present efforts to evoke the past. It is the moment of memory with which we consciously reconstruct images of the past in the selective way that suits the needs of our present situation" (Hutton xxi). Moreover, because memory can become remarkably pliable under the strain of crisis, ${ }^{\mathrm{vi}}$ the crisis and controversy of metal heaviness in the 90s makes for an ideal point from which to observe recollection at work. Further, as will be shown, when analyzing recordings, this memory-work should primarily be seen as a re-collection, a gathering-again of historical materials motivated by a present need to recall the past.

This harmonizes with Dick Hebdige's theory, postulating that the "raw materials" of subcultures are both material and ideological, and that "[e]ach subcultural 'instance' represents a 'solution' to a specific set of circumstances, to particular problems and contradictions" (81). However, whereas Hebdige's work emphasized the ways subcultures offer localized solutions to broader social problems, the black turn focused on the life of a subcultural aesthetic vis-à-vis its own internal problems and contradictions. To observe the ways in which recollection shapes subculture, one has to contend with the ways in which recordings operate as intertexts upon which intragroup memory works. Drawing from Julia Kristeva, Jeannette Marie Mageo explained that, "[i]ntertexts comprise the resources of intragroup memory" (13). From the recollection of these intertexts, something like a language forms and is used to constitute intragroup identity as such (Mageo 13-14). But to the extent that there is an extreme metal language, it is a very unstable one. 
Keith Kahn-Harris defined "extreme" metal as that which pursues all manner of transgression. In light of this, he found that the problem with pursuing a program of transgression is a resulting tendency towards instability. For the most part, this is not a bad thing. It is the aesthetic engine of all music genres. But this also means that subcultures are perpetually in crisis. Likewise, Deena Weinstein identified this problem, and found that the process of strategically constructing a shared subcultural past resembles the Protestant Reformation: "Both movements [thrash metal and Protestantism] charged that the established form had become corrupt through extravagance and both supported a return to the essential message, stripped bare of all adornment" (49). Though Weinstein was analyzing an earlier era of 1980s thrash reformism, which would lead to 90s death metal, the black turn exhibits the same counterhegemonic motion and demands the same solution: a rehabilitation of the present through a revival of past values. The black turn was a fundamentalist movement appealing to and drawing from the raw materials of history to imagine and create a metal blacker than death.

In most accounts of the black turn, two key matters are often muddled: the origin of the name "black metal" and the origin of the genre of music associated with the name. They are related, but not necessarily so. To suppose that there is a history of black metal as a genre prior to the 90s is already to share in the recollection created by the black turn. That is, the (pre)history of black metal was constituted retroactively. This is why Baddeley refers to it as the "genre that never was" (102). Note, however, that the claim is that it never was, but that there is no doubt that it now is.

Solving present problems with past materials, material and ideological, affects collective memory, thereby creating a new past. ${ }^{\text {vii }}$ For the black turn, recordings served as polyvalent intertexts, doing more than preserving the past; they also provided the material with and through 
which the intragroup's past was (re)constructed via new vectors of power. While the aim of this essay is to address the recollection of recordings deployed in the black turn, it is first necessary to understand how the black metal moniker and its attending ideology became articulated by a signature sound, since it was under this banner that new interpretations of the extreme metal canon were validated.

\section{THE OLD BLACK}

Old black metal had no sound of its own. It was not a genre. It was more of a marketing category used to differentiate Christian music from (purportedly) anti-Christian music (Weinstein 286287). In this way, black metal was once no different from earlier music dubbed Satanic, including folk, blues, and jazz. Nevertheless, while many types of music have been condemned in this way, heavy metal subcultures are different in that their members have made a tradition of playfully rearticulating rhetoric from out-groups. This is not to say that metal was the first to attempt such an innovation, but it was among the first to make it a central part of its subcultural identity and to articulate it with a distinctive sound.

One instructive point of comparison is the US band Coven, whose 1969 album Witchcraft Destroys Minds and Reaps Souls featured a cover depicting the band dressed in quasi-medieval garb, accessorized by a skull scepter and inverted crucifix. Along with songs like "Pact with Lucifer" and "Dignitaries of Hell," the final thirteen or so minutes of the album features the band reciting a black mass. Regardless, the music may have been black but it was not metal, sounding like a slightly more psychedelic Jefferson Airplane. Among later, heavier, more metal acts of the 1970s, like Led Zeppelin (England) and Black Sabbath (England), such dark symbolism would 
become more routine. Yet the first to directly reappropriate the black metal label was Venom (England), releasing Black Metal in 1982.

Though Venom's historical importance was recognized by the metal subculture prior to the emergence of the black metal genre, the fact is that they were understood as a primordial stage from which better, heavier, more extreme metal, such as death, had evolved. Unlike Coven, however, Venom were far less committed to the Satanic shtick, mixing in oblique references to devil worship amongst the usual rock themes of sex and drugs. This was the typical intragroup understanding of Satanic metal as merely part of a greater pastiche of countercultural signifiers (Walser 151-160; Weinstein 141-142).

The dearth of actual Satanists in the subculture had been an open secret, and knowledge of that fact undoubtedly drove fascination with the cult-like crimes of 1990s Norway. One of the greatest questions has been: why didn't the Norwegians understand that the diabolical icons typical of extreme metal were not entirely serious? Venom, for example, were hardly earnest or convincing in their Satanism; they are frequently compared to the band in the mockumentary This is Spinal Tap (1984). All the same, as Moynihan and Soderlind speculated, "Early Black Metal bands like Venom might not have been very serious about their image, but many young Norwegians may have been unable to realize this" (40). It is not difficult to imagine that the Faustian farce of a minor 80s metal band from England might, a decade later in Norway, appear as something other than what it was meant to be.

However, in the Kerrang! magazine cover story that brought the Norwegian scene to the attention of global metal audiences, the problem seems to be not an inability to see through the image, but an unwillingness. In the article, Mayhem's Aarseth cites Venom as an influence, and when the interviewer points out the obvious inauthenticity of Venom's act, Aarseth answers that 
Norwegians "choose to believe otherwise" (Moynihan and Soderlind 97). Likewise, in Baddeley's interview with Varg Vikernes of Burzum (Norway), Vikernes explained, "We are the way Venom and Bathory claimed to be. We believe what they pretended to believe" (206). ${ }^{\text {viii }}$ This demonstrates the willful ignorance of contradiction identified by Kahn-Harris as typical of black metal fans. Still, contradiction is hardly rare in music subcultures, or in any culture for that matter. There is nothing more contradictory, for example, about death metal artists denying personal diabolical belief or evil intent while fostering a prolific, focused, and elaborate aesthetics of Satanism and other despicable themes with their music. ${ }^{\text {ix }}$

More to the point, the intragroup crisis of the black turn was not so much about failing to understand the subtle, often ironic deployment of Satanic signifiers as it was about refusing to affirm what counted as a good, heavy sound. However, while the term "black metal" originates in Christian othering, and was taken up in the spirit of identifying with this imagined Other, this is not the case with all iterations of the form. Satanism per se is but one component of what was, and what continues to be, a more diverse ideological field organized around similar sounds (Hedge Olson 125-129; Weinstein 286-287). To understand fully what a counter-hegemonic recollection of an already transgressive past entails, one has to understand the emergence of true black metal as something more than anti-Christian or anti-social, neither of which would distinguish it as a genre or describe the breadth of themes present in today's black metal. One must understand that the black turn was largely anti-metal, and that this created the real split from which it could become an audibly distinct (re)collection.

Natalie J. Purcell's 2006 study of death metal revealed a number of fans who questioned whether metal had reached the ultimate extreme of heaviness in death. Even death metal artists sensed that their genre suffered under the weight of its own formulaic decadence. In a 2002 
documentary, members of Immolation (USA) explained why they strayed from standard death style, and detailed what had come of following death metal to its logical extreme. Commenting on their own move away from the 90s trend towards extremely complex yet barely melodic metal, the group's guitarist admitted, "I'd be in the car, put in a tape of one of my favorite bands, and I would have to listen for two or three minutes before I could even tell what song it was. It had gotten ridiculous. So we wanted, on the next album, to get back to basics, using fewer riffs with more hooks" (Zebub). Still, the most decisive proof of death metal's aesthetic bankruptcy may have come in 2006 when the Wall Street Journal published a piece lamenting how weak contemporary death metal had become compared to its 90s pinnacle, and especially mourning the decline of death metal's most distinguishing feature, the "Cookie Monster" timbre of its vocalists, which had been displaced by clean singing and even rapping. The author opined that death metal may have reached its heaviest extreme and thus been forced to return to other, lighter means of innovation (Fusili).

This is to say that not everyone followed the black turn. For most, the solution to the crisis was a return to what Weinstein would call a more Dionysian form of metal, making the music more accessible yet less heavy. Black metal, however, is the product of those who would not cede the fundamental value of heaviness. But how best to do such a thing?

Explaining what makes this type of music blacker than other metal, Darkthrone (Norway) drummer "Fenriz," a self-styled historian and mouthpiece for the Norwegian scene, told a reporter:

There wasn't a generic sound back then.... We had to decide ourselves what we deemed worthy of the black metal stamp. There were many "thrash" releases with a lot of "black" in them, whereas others had no "black" at all. This is not maths, 
so I can't say one plus one equals 30 . It had something to do with production, lyrics, the way they dressed and a commitment to making ugly, raw, grim stuff. (Campion)

But what, exactly, was the black sound they sought, and how did it differ from death metal? What is one listening for when one returns to the archive in search of ugly, raw, and grim sounds?

When it comes to recording, Joseph Russo explained: "black metal, in its varying and perpetually evolving states, employs a literal decomposition and decay of its own presence; that is, the sound of the metal itself is, in a sense, rotting away before our very ears" (95-96). In more concrete terms, the most readily discernible aesthetic maneuvers in the turn away from death metal were the preferences for amateurism over virtuosity and for low-fidelity production over high. But the black turn pursued not just any kind of amateur, low-fidelity work. Rather, it reified only particular sounds, creating an ugly, raw, grim aesthetic specific to the dominant sensibilities of extreme metal at the time. ${ }^{\mathrm{x}}$ By tracing the roots of black metal to some of its earliest recordings, the following section articulates some of the fundamental qualities of this sound as well as how it came to be.

\section{THE NEW BLACK}

Theodor Gracyk's analysis of Led Zeppelin's “D’Yer Mak’er” (1973) contended that listeners interpret sound based largely on their experience and understanding of the material field of reference offered by recordings. To listen to Led Zeppelin as a fan and to comprehend that “D’Yer Mak'er" is a musical joke, Gracyk explained, means hearing in the song a whole dialogue on guitar timbres with a field of relevant texts dating back to Rosie and the Originals' 
"Angel Baby" (1960). Understanding how one can listen to old recordings in order to recollect a history of a black metal sound where there was none before involves a similar effort. In this way, the solution presented by the black turn was not a mere return to old ways of doing things. It was not simple nostalgia; it was a counter-hegemonic way of listening to the past, a way that would locate and retrieve sounds that had been silenced and forgotten.

At the risk of oversimplifying or diminishing the brilliance of black metal, the easiest way to explain how music in the true black canon reads from a hegemonic position is to say that it verges on ridiculous. It doesn't seem possible that anyone sincerely, un-ironically enjoys such a thoroughly "bad" sound. Even, or especially, by the standards of extreme metal fans with a broad palate for transgressiveness, the sound of black metal was hard to digest because it valorized many of the sounds, images, and ideas from metal's past that most would prefer to forget. Yet, as Kahn-Harris argued about black metal imagery, it would be a mistake to think of this as a form of camp. There is remarkably little ironic distance between the musicians and the music, as well as for many fans around the world for whom black metal is an important component of their identity. ${ }^{\mathrm{xi}}$

In this regard, Venom are less significant for adopting the black metal moniker and more significant as an example of what the reformists of the black turn wanted to hear. Further, Venom were hardly the only ones of this sort to be redeemed through the recollections of the black turn. They are only the first point in a new constellation of similarly reclaimed materials, including records from Hellhammer (Switzerland), Bathory (Sweden), and Mayhem (Norway). These are certainly not the only relevant texts, but they are representative enough to give a sense of how the larger constellation of recordings could be recognized. 
Addressing Venom's talent as musicians, Baddeley wrote simply, “[t]echnically, Venom stank" (125). But, he also explains, they weren't aiming to be good. Like punk artists, they were against the slickness of mainstream music and wanted to make something truly hard to like, a tried and true tactic of heaviness. The mistake they made, however, was believing that production values matter less than they do. That is, a sloppy, amateurish performance or composition is one thing, but a sloppy and amateurish recording of such a song or performance can be a bridge too far. Venom albums were so poorly recorded that, even in their greatest hits collection, Mathias Mader noted lackluster production values as a cause of the band's decline. The same was true for Venom's Swiss contemporaries, Hellhammer.

Prior to the black turn, Hellhammer were mostly known as the worst heavy metal band to ever make a record (Sharpe-Young 185). Not only are the Hellhammer albums poorly recorded, the songs are extremely basic, repetitive, and badly performed—difficult to enjoy even for those who like things in that vein. The band eventually called it quits, reforming later as Celtic Frost. In the 1990 CD re-issue of the original Hellhammer recordings, Apocalyptic Raids, Hellhammer/Celtic Frost frontman Tom G. Warrior wrote:

Hellhammer lasted on us almost like a curse. Even though Hellhammer was the very reason we had thought over our goals and conceived the Frost, HH's leftovers kept being mighty rocks in our way. Many voices saw Frost as the same band with just a name-change. The lack of musical quality in $\mathrm{HH}$ made it almost impossible for us to get an unbiased reaction to Frost. To make a long story short, it almost killed all our work and dreams.

Regardless, Warrior was obviously convinced enough of the merits of this embarrassment to reissue it and, moreover, he was right. Black metal would turn towards this seemingly campy 
ineptitude with shocking sincerity, reproducing Venom and Hellhammer a hundredfold, turning formerly denigrated recordings into sublime examples of a new genre.

Unlike Venom and Hellhammer, however, Bathory, the final group to be considered in this proto-black metal origin story, did not go through a period of embarrassment and failure. Bathory stands somewhere between the purposefully raunchy Venom and the accidentally grotesque Hellhammer. They were among the first to prove that there was an audience tiring of death metal and anxious to hear something completely different. All the same, this innovation was not entirely by design.

As the story goes, a record company employed teenage metal fan Thomas Forsberg to screen music for a compilation of Swedish metal. With this connection, Forsberg convinced the label to include two songs from his own band, despite the fact he didn't actually have a band, or recordings, or songs. Surprisingly, the label agreed, Bathory was born, and two hastily made songs were released on the Scandinavian Metal Attack (1984) compilation. Frosberg's amateur effort stood out among a string of otherwise acceptable, run-of-the-mill thrash and death metal tracks, and Bathory soon earned an international following (Moynihan and Soderlind 16).

Forsberg, remembering the sessions for his first recordings, recalls the challenge to record a full-length album without a real band, and with less than $\$ 700$ :

We knew about this place that was originally a garage or a private car workshop turned into a demo studio. ... It had some rather primitive recording equipment, a home made 8-track table, two small recording machines in one room, plus this switchboard thing on the wall with miles of stereo cords hanging plugged into eight times eight rows of holes. 
... Essentially it was a private small demo studio very likely best suitable for acustic [sic] and vocal type of material, and maybe light pop music. But nothing like BATHORY had ever been recorded there. We had to adapt to the place and its limitations at the same time the place had to adapt to us. ("Bathory")

Forsberg went on to explain that, unlike the standard metal aesthetic of hyper-realistic drum sounds, the Bathory sessions recorded just the sound of the drums in the room and used a limiter to flatten the unruly dynamics. The resulting sound, like beating on cardboard boxes, is emulated by black metal purists to this day. ${ }^{\text {xii }}$ Further, Bathory's guitar and bass were cheap beginners' models, and they had only a single, 20-watt guitar amplifier, which, in a live setting, is not enough volume to overpower conversation, never mind drumming and screaming. On record, the guitar timbre is pinched, full of mid-range frequencies, the opposite of death metal's bass-heavy timbres and, like the drum timbre, remains a mainstay of the true black aesthetic.

Additionally, low-budget recording meant more than a lack of professional equipment. It also meant a lack of time. On a short production schedule, Bathory couldn't refine the recorded performances with multiple takes, punch-ins, over-dubs, edits, and other techniques used to create the machine-like tightness of big-budget metal productions. So, instead of an inhuman composite of a performance, which had become the norm, the nascent black aesthetic on albums such as Bathory's included not just a lo-fi texture, it also included the sound of raw, amateur, performances, which were flaunted, intentionally or otherwise, on albums from Venom, Hellhammer, and Bathory.

By affirming these sounds, the black turn hinged on the desire to witness and create the sound of metal's putrescence. The new black was found by listening less for Satanic lyrics and more for some audible clue about alternatives to the dominant means and relations of subcultural 
production. The persuasiveness of this recollection can be read from the way a Mayhem recording from the $80 \mathrm{~s}$, prior to the black turn, was repackaged and repurposed in the $90 \mathrm{~s}$, playing to the black turn.

Unlike Hellhammer and Bathory, Mayhem were one of the first bands since Venom to claim the black metal tag. Though they originally thought of themselves as a death metal act, they quickly made the turn towards black metal. Yet the change was less in their sound than in the way they framed their sound. In 1993, they repackaged and rereleased their 1987 album, Deathcrush, with a new graphic on the back, a crossed-out picture of Scott Burns surrounded by the words "no fun," "no core," "no mosh," "no trends."

Burns was an engineer and producer credited with creating the Florida death metal sound that boomed in the early 1990s. His agenda-setting work with acts including Death (USA), Obituary (USA), and Suffocation (USA) are classics of the era. To some degree, the crisis of death metal was the outcome of Burns' style and its influence. His interpretation of heaviness defined the genre at the time, specifically the combination of exaggerated, muddy bass; tightly focused drums; prominent vocals; and inhumanly precise performances—-the opposite of the piercing, mid-range guitars; roomy drum sounds; buried vocals; and all-too-human performances found on Deathcrush. Mayhem's reissue shows a new consciousness of how the black turn could reposition old recordings. As a death metal album, Deathcrush could not compete with the heaviness of Burns-type records. Read alongside the 90s fascination with Venom, Hellhammer, and Bathory, however, Mayhem's first albums retrospectively epitomized the new black.

It may be tempting to conclude that the black turn only made a virtue of necessity. Valorizing low-budget amateurism rather than big-budget virtuosity is suspiciously convenient 
for artists from the margins of a subculture desiring to be heard by the center. But such a view does not account for the wider metal audience's desire to hear such things.

The decline of death metal and concomitant black turn were affected by listeners' situated experiences of metal recordings. It must be considered that, for metal and other music of the era, the spread of tape trading made it possible for several decades of music to be shared across continents, facilitating a global conversation about the best direction for metal's future with regard to its present and past. ${ }^{\text {xiii }}$ Subverting the official, commercial channels of distribution, tape trading was the primary network for underground music and musicians. This expanded the audience for metal, and allowed music from marginalized regions to circulate more broadly. Trading set the stage for the black turn by making the archive of metal recordings more readily available as well as by expanding what would be included in that archive; for listeners to tire of death metal, it must first have become overrepresented in this network.

At the same time, however, the 1990s were also the years of digital audio's ascendancy. In that era, vinyl and tape circulated alongside compact discs, and tape trading networks began morphing into digital filesharing networks. That is, the material vectors of subcultural memories and the texts supporting them were fragmenting, multiplying, and recombining in ways that would affect listeners' recollections of the past and visions for the future. Black metal coalesced around an emerging nostalgia for the authenticity imagined to infuse classic recordings from previous generations. This type of nostalgia and the way it attributes authenticity to noisy, lowfidelity recordings also occurs in other music subcultures. ${ }^{\text {xiv }}$ Yet the black turn is significantly different in that it was not straightforwardly nostalgic. The sound could not well be described as "retro." Rather than valorizing established classics, it (re)collected the past counterhegemonically, re-evaluating "bad" sounds and remembering a genre that never was, thus 
bringing it into being. Moreover, examining specific cases through which lo-fi aesthetics evolve is instructive insofar as it illustrates the fact that "lo-fi" is not itself a sound, but rather, that what audiences interpret as a raw, noisy, or low-fidelity sound is relative to their culture of listening. Authenticity, in this case, lies less in recordings themselves, and more in their aesthetically exigent recollection.

\section{CONCLUSION}

The black turn took place for three reasons: the globalization of the subculture, the exhaustion of old aesthetic paradigms, and an upheaval in the dominant means of production and distribution. Of special interest to scholars of popular music should be the connection between the rhetoric of subcultural aesthetics, like "extreme," "heavy," "black," or "raw" in this case, and the material artifacts to which these terms become dis/articulated. Such terms are more than subcultural argot; they point to real, audible phenomena and, more importantly, to the ways listeners understand their meaning and value.

The meaning of metal, what makes certain genres of metal more extreme than others, and how one hears and experiences heaviness, derive from the (re)collection of recordings. Walser, therefore, was correct in claiming that heavy metal cannot be thought of as a coherent genre in and of itself. It is, instead, a terrain upon which many conflicts and conversations occur. This terrain, as shown above, is grounded in the production, circulation, and recollection of recordings. However, despite the rhetoric of a return to heavy metal's core values, the viability of black metal ultimately proves there is no absolute canon of master works nor is there a final interpretation of them. 
Still, the idea that there is a heavy metal code or language is common in metal studies. When it comes to genre development and differentiation, the overall theoretical proposition is that all metal can be understood with regard to where it fits between two semiotic poles. For Walser, the tension is between freedom and control. For Weinstein, it is between Chaotic and Dionysian values. For Kahn-Harris, it is a matter of transgressive cultural capital as opposed to the mundane. And, more to the point, for Berger and Fales, it is about light versus heavy sound. These concepts are indeed useful for synchronic analysis, but in theorizing the black turn as a historical transition, it becomes clear that the material signifiers of freedom, chaos, transgression, heaviness, and the like are subject to the vicissitudes of collective memory, and can be recollected to align quite differently. In other words, echoing Ludwig Wittgenstein, there is no meta(l)-language, only a play of audible differences made meaningful by the silencing or forgetting of other differences.

In analyzing the black turn, it can be seen that recordings do more than capture and communicate moments from the past. As artifacts unto themselves, they are the objects with which aesthetic innovations are discovered and disseminated. Though sonic signifiers of genre may be theorized as a sort of language, the grammar and vocabulary of that language are volatile, subject to changes in the means of production and distribution as well as to changes in audience demographics and tastes.

The appeal of black metal in the 90s, not to mention its subsequent popularization and diffusion within and beyond metal subcultures, can neither be reduced to a fascination with the spectacle of the Norwegian crimes nor with its diabolical or anti-social resonances. The black turn was a criticism of and an alternative to the hegemony of heaviness at a moment of crisis in the history of extreme metal. This moment was recognized and addressed through a distinctly 
counter-hegemonic mode of nostalgic recollection. Establishing a recognizable black metal aesthetic entailed drawing from preexisting yet undesired possibilities within the canon, opening a new arena of allowable sounds, finding heaviness where there was none before, and thereby creating a sound blacker than death.

${ }^{i}$ The first major article within the subculture appeared in Kerrang! metal magazine in 1993. This was preceded by coverage in the mainstream press, initiated by a series in Norway's Bergens Tidende newspaper earlier that same year.

${ }^{\text {ii }}$ Aarseth, a.k.a. "Euronymous," was also murdered by Varg Vikernes, a.k.a., "Count Grishnack," from the equally influential black metal act Burzum (Norway).

iii See the works of Baddeley; Christe; Hagen; Kahn-Harris; Konow; Moynihan and Soderlind; Sharpe-Young for examples.

${ }^{\text {iv }}$ See the works of Hagen; Kahn-Harris; Moynihan and Soderlind; Wallach et al. for more information on this point.

${ }^{v}$ Nonetheless, although the popularity of American death metal would decline, death metal music, particularly in its more politicized strains, would gain considerable popularity in developing countries, particularly in South America and parts of Asia, where artists used the form to voice their own, local politics (see Wallach et al.). Further, black metal as a genre has since evolved to address politics as well as other themes outside of Satanism, fantasy, and the occult, including history and naturalism (see Kahn-Harris; Hedge Olson).

${ }^{\mathrm{vi}}$ See Biesecker; Hebdige; Roth and Salas; Suleiman.

${ }^{\text {vii }}$ See Fentress and Wickham; Halbwachs; Hutton. 
${ }^{\text {viii }}$ Vikernes has responded to the book, stating that he does not remember giving the interview and that he disagrees with a number of statements attributed to him. However, this is not one of them (see http://www.burzum.org/eng/library/lucifer_rising_review.shtml).

${ }^{\text {ix }}$ Arguably, a metal subculture without contradiction would be comically absurd, as can be seen in the animated television series Metalocalypse.

x Today, this classic black metal production aesthetic is often referred to as "necro" style. ${ }^{x i}$ See Hagen; Hedge Olson; Kahn-Harris.

${ }^{\text {xii }}$ So similar is the sound to cardboard that the double bass drum passages were literally performed on cardboard boxes because they didn't have a second bass drum (see www.bathory.se).

${ }^{\text {xiii }}$ See Christe; Kahn-Harris; Moynihan and Soderlind; Wallach et al.

${ }^{\text {xiv }}$ See Bennett; Dolan; Eley; Reyes. 
Works Cited

Baddeley, Gavin. Lucifer Rising: Sin, Devil Worship, and Rock 'n' Roll. London: Plexus Publishing, 1999. Print.

"Bathory." bathory.se. n.p., n.d. Web. 1 May 2006.

Bennet, Andy. "Music, Media and Urban Mythscapes: A Study of the 'Canterbury Sound."' Media, Culture and Society 24.1 (2002): 87-100. Print.

Berger, Harris M. Metal, Rock, and Jazz: Perception and the Phenomenology of Music Experience. Hanover: UP of New England, 1999. Print.

Berger, Harris M., and Cornelia Fales. "'Heaviness' in the Perception of Heavy Metal Guitar Timbres: The Match of Perceptual and Acoustic Features Over Time.” Wired For Sound: Engineering and Technologies in Sonic Cultures. Eds. Paul D. Greene and Thomas Porcello. Middletown: Wesleyan UP, 2005. 181-197. Print.

Biesecker, Barbara. "Remember World War II: The Rhetoric and Politics of National Commemoration at the Turn of the 21st Century." Quarterly Journal of Speech 88.4 (2002): 393-409. Print.

Campion, Chris. "In the Face of Death." The Observer. The Observer. 19 Feb. 2005. Web. 1 May 2006.

Christe, Ian. Sound of the Beast: The Complete Headbanging History of Heavy Metal. New York: Harper Collins, 2003. Print.

Dolan, Emily I. “'This Ukulele Tells the Truth’: Indie Pop and Kitsch Authenticity.” Popular Music 29.3 (2010): 457-469. Print. 
Eley, Craig. "Technostalgia and the Resurgence of Cassette Culture." The Politics of Post-9/11 Music: Sound, Trauma, and the Music Industry in the Time of Terror. Eds. Joseph P. Fisher and Brian Flota. Burlington: Ashgate Publishing, 2011. 43-55. Print.

Fentress, James, and C. J. Wickham. Social Memory: New Perspectives on the Past. Cambridge: Blackwell, 1992. Print.

Fusili, James. "That's Good Enough for Me: Cookie Monsters of Death Metal Music.” Wall Street Journal. Wall Street Journal. 1 Feb. 2006. Web. 1 May 2006.

Gracyk, Theodor. Listening to Popular Music, Or How I Learned to Stop Worrying and Love Led Zeppelin. Ann Arbor: U of Michigan P, 2007. Print.

Halbwachs, Maurice. On Collective Memory. Trans. L. Coser. Chicago: U of Chicago P, 1992. Print.

Hagen, Ross. "Musical Style, Ideology, and Mythology in Norwegian Black Metal." Metal Rules the Globe: Heavy Metal Music Around the World. Eds. Wallach, Berger, and Greene. Durham: Duke UP, 2011. n. pag. E-Book.

Hebdige, Dick. Subculture: The Meaning of Style. London: Routledge, 1979. Print.

Hedge Olson, Benjamin. I Am the Black Wizards: Multiplicity, Mysticism and Identity in Black Metal Music and Culture. MA thesis. Bowling Green State University, Bowling Green, KY, 2008. Web.

Hutton, Patrick H. History as an Art of Memory. Hanover: UP of New England, 1993. Print.

Kahn-Harris, Keith. Extreme Metal: Music and Culture on the Edge. New York: Berg, 2007. Ebook.

Konow, H. David. Bang Your Head: The Rise and Fall of Heavy Metal. New York: Three Rivers Press, 2002. Print. 
REYES: BLACKER THAN DEATH 24

Mader, Mathias. Liner notes. Venom. From Heaven to the Unknown. Snapper Music, 1999. CD. Mageo, Jeanette Marie. "On Memory Genres: Tendencies in Cultural Remembering." Cultural Memory: Reconfiguring History and Identity in the Postcolonial Pacific. Ed. J. M. Mageo. Honolulu: U of Hawaii P, 2001. 11-30. Print.

Moynihan, Michael, and Didrik Soderlind. Lords of Chaos. Los Angeles: Feral House, 1998. Print.

Purcell, Natalie J. Death Metal Music: The Passion and Politics of a Subculture. Jefferson: McFarland and Company, 2003. Print.

Reyes, Ian. "The Raw and the Produced: (Re)Producing Hardcore Authenticity in the Studio." Culture Critique 1.1 (2008): n. pag. Web. 1 May 2006.

Roth, Michael \& Charles Salas. Disturbing Remains: Memory, History, and Crisis in the Twentieth Century. Los Angeles: Getty Research Institute, 2001. Print.

Russo, Joseph. "Perpetue Putesco: Perpetually I Putrefy." Hideous Gnosis: Black Metal Theory Symposium 1. Ed. N. Masciandaro. Creative Commons, 2010. 93-104. Print.

Sharpe-Young, Gary. A-Z of Black Metal. London: Cherry Red Books, 2001. Print.

Suleiman, Susan Rubin. Crises of Memory and the Second World War. Cambridge: Harvard UP, 2006. Print.

Wallach, Jeremy, Harris M. Berger, and Paul D. Greene. "Affective Overdrive, Scene Dynamics, and Identity in the Global Metal Scene." Metal Rules the Globe: Heavy Metal Around the World. Eds. Wallach, Berger, and Greene. Durham: Duke UP, 2011. n. pag. E-Book.

Walser, Robert. Running with the Devil: Power Gender and Madness in Heavy Metal Music. Hanover: U of New England P, 1993. Print.

Warrior, Thom G. Liner notes. Hellhammer. Apocalyptic Raids. Futurist Records, 1990. CD. 
REYES: BLACKER THAN DEATH 25

Weinstein, Deena. Heavy Metal: The Music and Its Culture. Boston: Da Capo Press, 2000. Print.

Zebub, Bill. Death Metal: A Documentary. Grimoire Films, 2002. DVD. 